\title{
PROJECT-BASED LEARNING IN THE SUBJECT OF ENERGY AND SUSTAINABLE DEVELOPMENT
}

\author{
I. Marton Lluch¹, J.F. Villanueva², S. Gallardo², S. Carlos ${ }^{3}$, A.I. Sánchez ${ }^{1}$ \\ ${ }^{1}$ Universitat Poltècnica de València. Departamento de Estadística, Investigación Operativa \\ Aplicadas y Calidad (SPAIN) \\ ${ }^{2}$ Universitat Poltècnica de València. Departamento de Ingeniería Química y Nuclear (SPAIN) \\ ${ }^{3}$ Universitat Poltècnica de València. Departamento de Ingeniería Q (SPAIN)
}

\begin{abstract}
The standards and guidelines for quality assurance in the European Higher Education Area (EHEA) lay down that one of the keys to combining learners' knowledge and skills is the implementation of new more student-centred methodologies, and learning based on competences. One of the most widely used and effective active learning methodologies is Project-Based Learning (PBL). This is a practical pedagogical methodology in which the student carries out a project focused on solving a real problem by applying the theoretical concepts from a practical point of view.

In this work, projects implanted using the PBL methodology are aligned with the Agenda 2030. This Agenda for Sustainable Development, approved in 2015, establishes that the universities must play a major role in compliance with it, in due consideration of their responsibility in relation to training, research, relations with society and a model for higher education governance. This agenda contains 17 Sustainable Development Goals (SDGs). This proposal is focused on Goal 7, "Affordable and Clean Energy".

In the framework of the PBL methodology and integrating the SDGs of the Agenda 2030, the main goal of this work is the development of project-based learning in the subject "Energy and Sustainable Development" in the bachelor's degree in Energy Engineering at the Universitat Politècnica de València. The paper described the developed methodology, the results achieved and the initial conclusions obtained.
\end{abstract}

Keywords: Project-based learning, Energy, Sustainable Development Goals, methodology.

\section{INTRODUCTION}

The European Higher Education Area (EHEA) quality regulations lay down that the key to combining knowledge and skills is to implement new active student-centred teaching methods and competencebased learning [1]. One of the most effective and frequently used active learning methods is projectbased learning ( $\mathrm{PBL}$ ), in which the students are asked to carry out a project involving a certain amount of investigation to solve a real problem by applying theoretical concepts from a practical point of view [2].

The characteristics of this method are based on an actual case and it is focused on the student and his learning. ABP promotes student commitment to learning and his work group. One of its fundamental aspects is that it involves different areas to promote interdisciplinary skills[3].

In the Energy Engineering degree (GIE in Spanish) of the Universitat Politècnica de València (UPV), the present authors detected defective basic concepts in different subjects that hindered the development of specific competences. The Chemical and Nuclear Engineering Department (DIQN in Spanish) the Applied Statistics and Operative Research and Quality Department (DEIOAC) worked together to identify weaknesses, strengths and opportunities in some GIE subjects and found that firstyear statistics and second-year Sustainable Development and Energy offered clear opportunities to improve the teaching system. They proposed to optimize the didactic resources by promoting the synergies between both subjects. In fact the problem was due to applying statistical techniques to energy generating problems. In previous work [4], the present authors gave the activities involved in the first-year subject and the results obtained by the method. Activities related to wind power generation using statistical distribution to characterize the wind speed frequency or Weibull distribution. In previous work we also found that the students are particularly motivated by renewable energies, like wind. Joining these two facts together we were able to identify a weakness (lack of a 
technical and theoretical foundation) and a strength (an attraction to renewable energies) in these subjects.

It is also important from the perspective of projects that the context of the 2030 Development Agenda and the Sustainable Development Goals (SDG) [5] be considered. In 2015 the UN unanimously agreed on the 2030 Development Agenda to tie sustainable development to economic, social and environmental processes by means of the 17 SDG, which represent a plan in favour of persons, the planet and prosperity in the hope that by 2030 we will have placed the world and its societies on the road to a better future (Fig. 1).

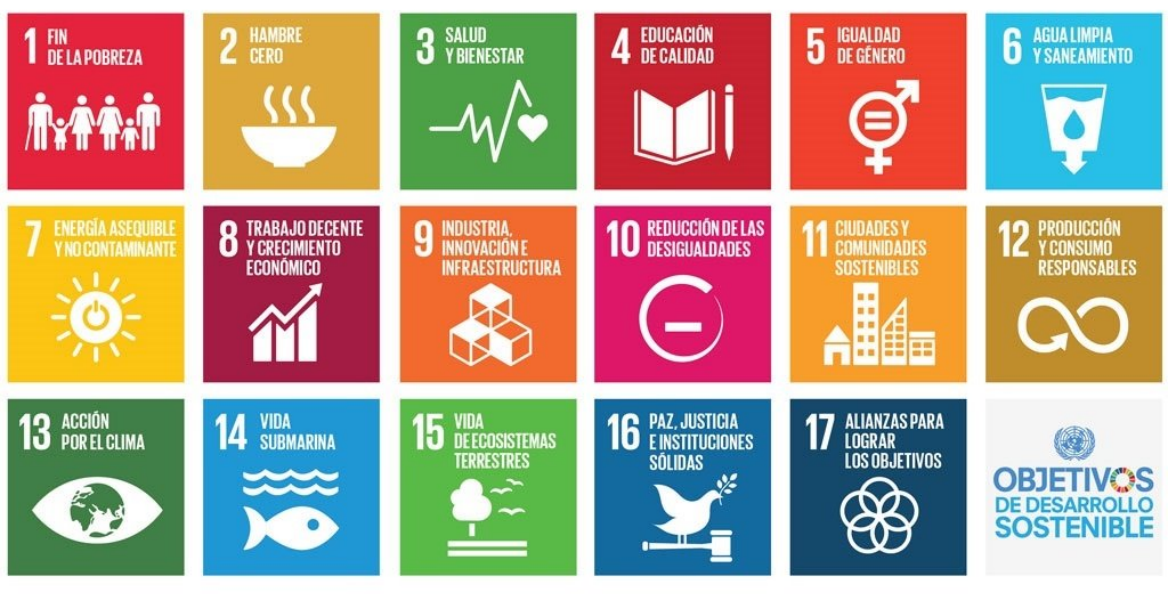

Figure 1. Sustainable Development Goals.

These SDGs place quality education as a key factor in sustainable development by means of SDG 4 . Some of the goals proposed directly involve the universities. For example, Goal 4.7 considers that universities play a fundamental role in providing solutions, knowledge and innovative ideas and are responsible for training the present and future people who will have to implement the SDGs, serve as a model of how to support, adopt and implement SDGs in governance, management policies and university culture and develop intersectorial leaderships to orientate the GDS.

Also, in the context of the degree course in which this innovation is studied it is important to align the work of both subjects with GDS 7, clean and affordable energy. These subjects can be used as a powerful tool to develop GDS 7 in decision making when designing and planning clean energy systems that make sustainable development possible.

In the context of PBL and the SDGs of the Agenda 2030, the main objective of this work was to develop a PBL system in the Energy and Sustainable Development subject in the UPV's Energy Engineering degree course. This paper thus describes the method developed, the results obtained and the initial conclusions obtained.

\section{OBJECTIVES}

The general aim was to design activities for project-based learning and establish methods and define appropriate evaluation techniques for this type of learning in the Energy and Sustainable Development subject, to strengthen the use of the results of the Energy Engineering degree statistics subject.

The work was carried out in the framework of the UPV's Educational Innovation and Improvement between 2018 and 2020 applied to the GIE degree course. The project is now in its second year. This paper describes the activities, method and the results obtained so far, also a preliminary report on some of the results obtained from implementing these activities.

The specific work objectives were as follows:

- To check whether the activities carried out in Statistics were effective in reaching the basic knowledge necessary.

- Design specific activities for Energy and Sustainable Development that could be transversally integrated with the learning aims of the subject previously achieved in Statistics.

- Align the activities in SDG 7 to foment the use of renewable energy sources. 
- Design activities that provide the students with specific competences and the transversal competences of Energy and Sustainable Development.

The context and development of the innovation, the method and the initial results are described in the following sections. The Conclusions are given in the final section.

\section{INNOVATION DEVELOPMENT}

Following the experience in the 2018-19 year in the second year of the PIME project in which this work is included, we applied the PBL method to the second-year GIE course Energy and Sustainable Development (E\&SD).

In recent years it has been detected that students find it difficult to apply theoretical concepts learned in the first year in Statistics to practical problems in the second year subject. This means the opportunity was lost to use the synergy between both subjects to teach some competences more effectively. In this context the main aim of this work was to develop a project that integrated the specific transversal competences of these subjects so that the students could apply theoretical concepts to a real situation. Using statistical tools, the students develop two capacities: calculating and working on an energy sector project.

The experience proposed for E\&SD was the design of a terrestrial wind farm by means of a computer practice session with the following aims:

- Preliminary design of a wind farm and estimation of the power it could produce.

- Determine the project's economic viability.

The practice session lasts 3 hours and begins with the presentation of the objectives of the exercise and a brief description by the lecturer of the energy situation in the Valencia Community in terms of renewable energy production. The Community's Wind Power Plan is briefly described, plus the different districts it is divided into, with the main wind farms, their capacities, the year they were built and the builder, with the idea that the students get a good overall conception of the present situation. There is then a brainstorming session to try to determine the minimum requisites that must be satisfied to select a wind farm site. This part is quite interesting because the students are able to identify most of the factors that have to be considered. The lecturer restricts himself to classifying the factors identified into three main categories:

- Administrative requisites.

- Technical requisites.

- Environmental requisites.

The practical part of the problem is then approached. The task is to design a $16 \mathrm{MW}$ wind farm for an appropriate site in Valencia. The area chosen is the Community's Wind Power Zone 4 (which includes the municipalities of Albocàsser, Tirig, Catí, Xert, etc).

It is proposed to consider a certain model of wind turbine belonging to a commercial manufacturer. The students are given a catalogue with the necessary technical specifications to solve the problem: power curve, nominal power, rotor diameter, spinner height, and overall power losses. When identifying the technical requirements it is determined that the separation between turbines is an essential parameter to reduce inter-turbine interference. One method of reducing these losses to $5 \%$ is to leave a minimum of two rotor diameters between the turbines. Considering the nominal power of each generator and the total nominal wind farm production, the students determine the required number of turbines and the farm's total length, supposing that all the turbines are in a single row. This is another essential parameter in the exercise for it determines the minimum length of the hillsides to be considered for suitable sites. They are also reminded of the importance of the hillside's orientation with respect to the prevailing wind.

With these two ideas, hillside length and prevailing wind direction, the second part begins. This is carried out independently by the group. The students are given the necessary tools to propose possible sites for the wind farm: a map of the Valencia Community (online viewer version) and a Global Wind Atlas. To mark out geographically the possible solutions the zone was reduced to the municipal limits between Catí and Albocasser using the Valencia Map Institute's viewer https://visor.gva.es/visor/ or the Visor Map Windows 5. 
The students must look for hillsides that satisfy the orientation, length and height requirements. This part too is interesting since it involves a search with multiple solutions and the students find that it involves an elimination process together with a trial and error process since it is impossible to tell from a map if a hill of the correct size is facing the right way for the prevailing wind until consulting the Wind Atlas.

The environment is an additional restriction. An insistence is made on not being able to propose sites within certain areas: Red Natura 2000 and Espacios Naturales Protegidos (Fig. 2).

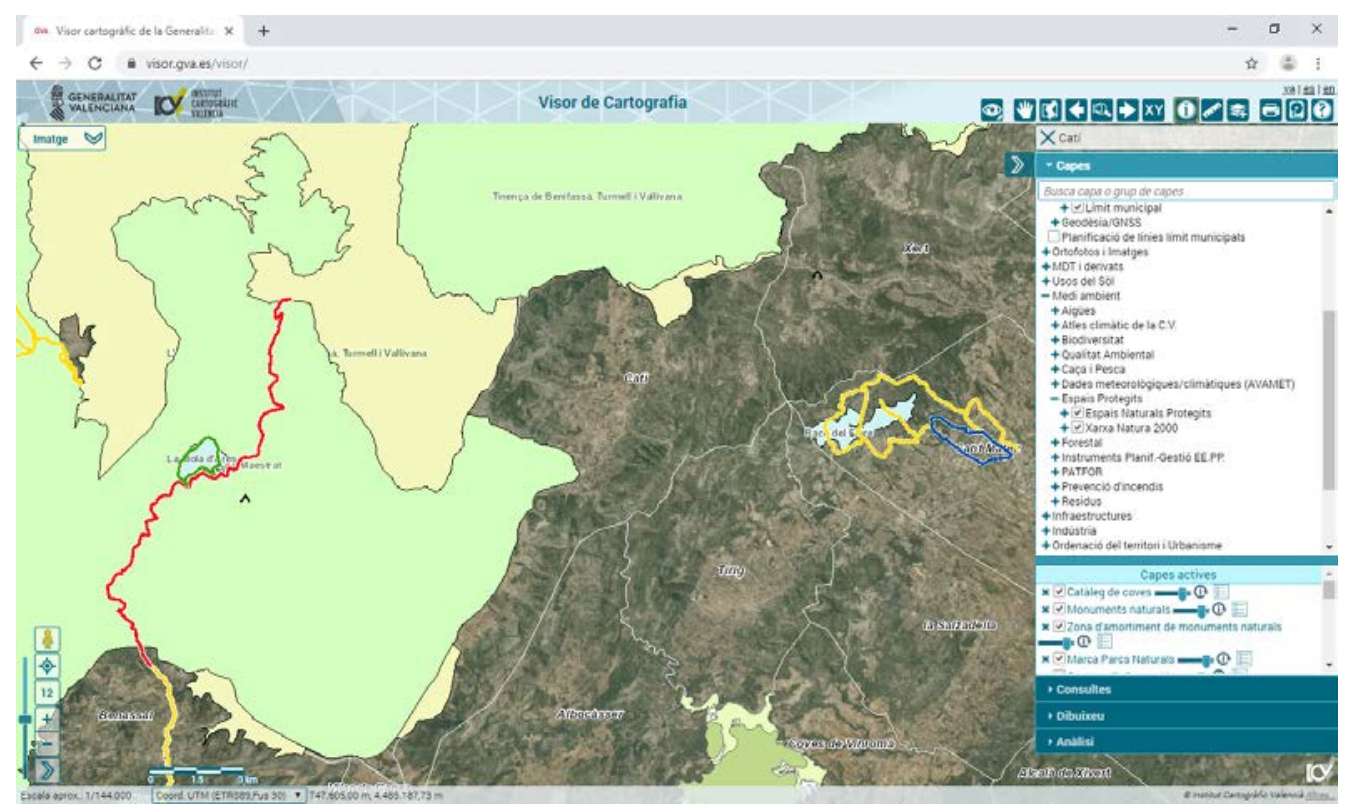

Figure 2. Protected areas in the zone of interest. Valencia map viewer.

They are given a maximum of 15 minutes to locate a hill that complies with all the pre-defined criteria. Those who cannot find one in the given time are assigned one to continue the exercise (Fig.3). The wind conditions are checked with the help of the Global Wind Atlas (Fig.4)

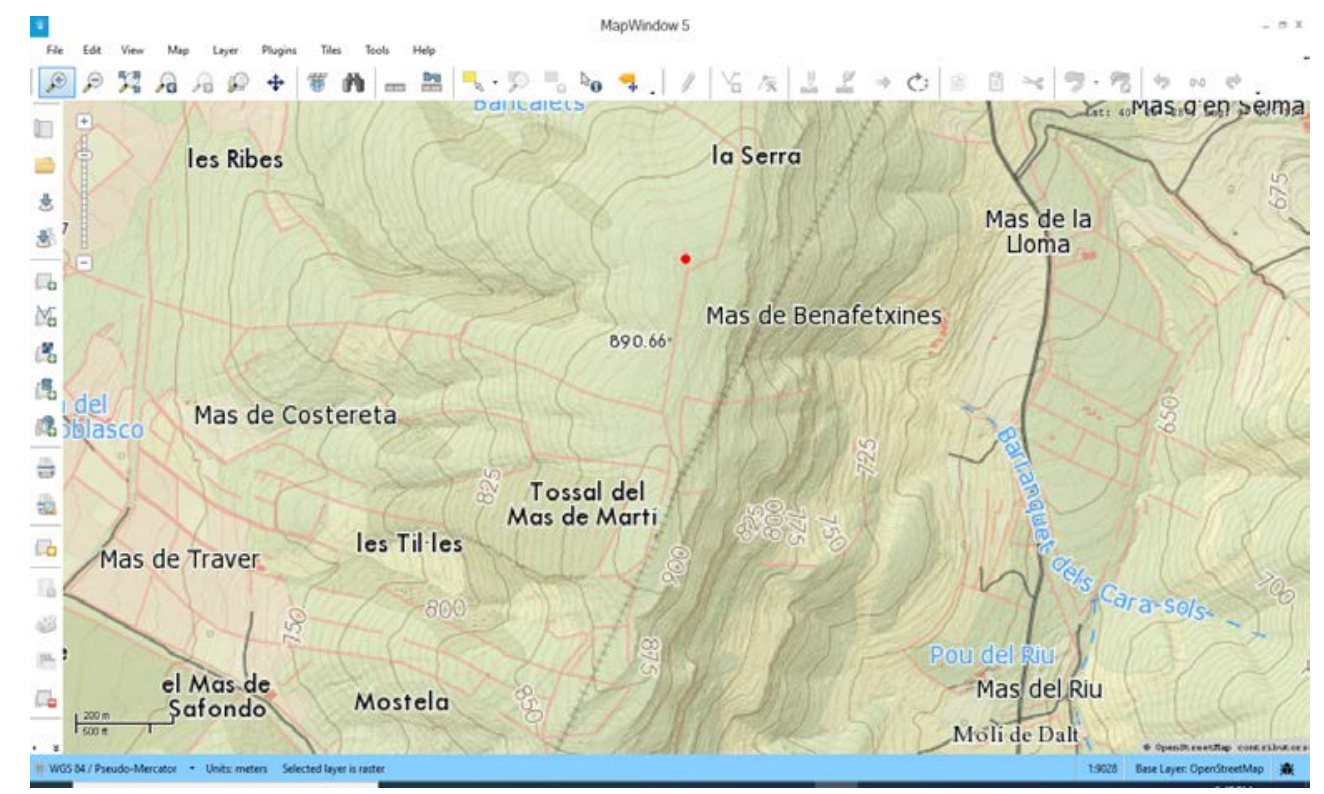

Figure 3. Proposed site. Valencia Map Viewer. 


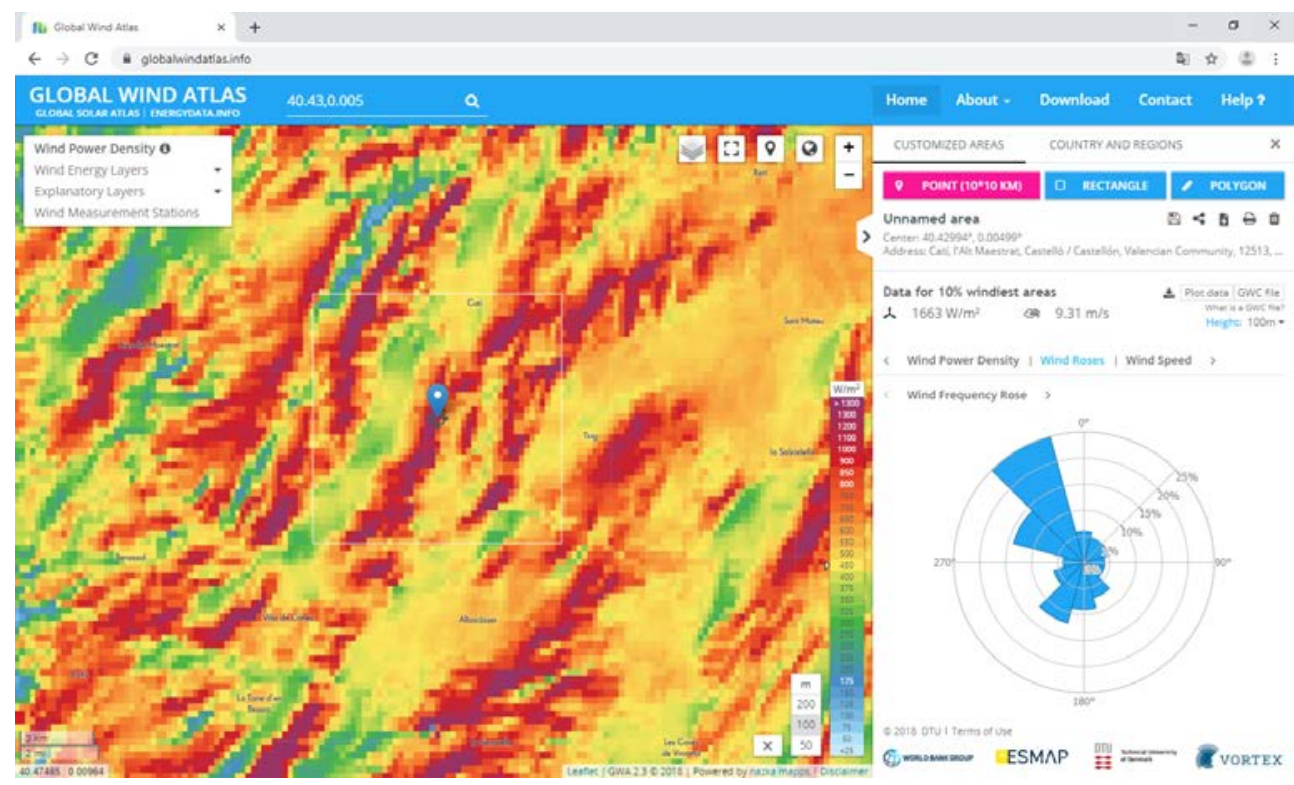

Figure 4. Power density of proposed site. Global Wind Atlas.

The wind parameters of interest consulted in the Global Wind Atlas are: average wind speed, power density, wind rose in frequencies and parameters $\mathrm{A}$ and $\mathrm{K}$ of the Weibull distribution.

At this point they require their knowledge of the statistics acquired in the first year as they must relate the Weibull distribution concept with what they have learned in this subject. Time is saved as a result of the vertical coordination between both subjects since it is not necessary to repeat the concept. In Statistics the students also have studied the significance and use of this type of distribution with examples provided by the second-year subject lecturers.

After obtaining all the information they calculate the energy produced by the wind farm, drawing the power curve, the Weibull distribution for the proposed site and the number of turbines.

To give them extra motivation a ranking is made of the energy calculated by each student, obtaining among the whole group a geographical classification according to the chosen site and the gross power produced.

The final part of the practice involves determining whether the wind farm will be an economic proposition, for which the VAN and TIR parameters are calculated on the RETSCREEN program using the information obtained in the previous phase (Fig.5).

Considering all the calculations made in each part of the exercise, the students acquire the competence to assess the wind farm's economic viability. At this point, almost at the end of the exercise, the profitability of each site is compared and they are quite surprised to learn that a wind farm project may not be viable economically simply by deciding to build it in the wrong place.

The first experience of this kind took place during the year 2019-20 and was highly positive as regards the students' response to the project and in the additional motivation represented by the desire to present a more profitable project than their other classmates. 


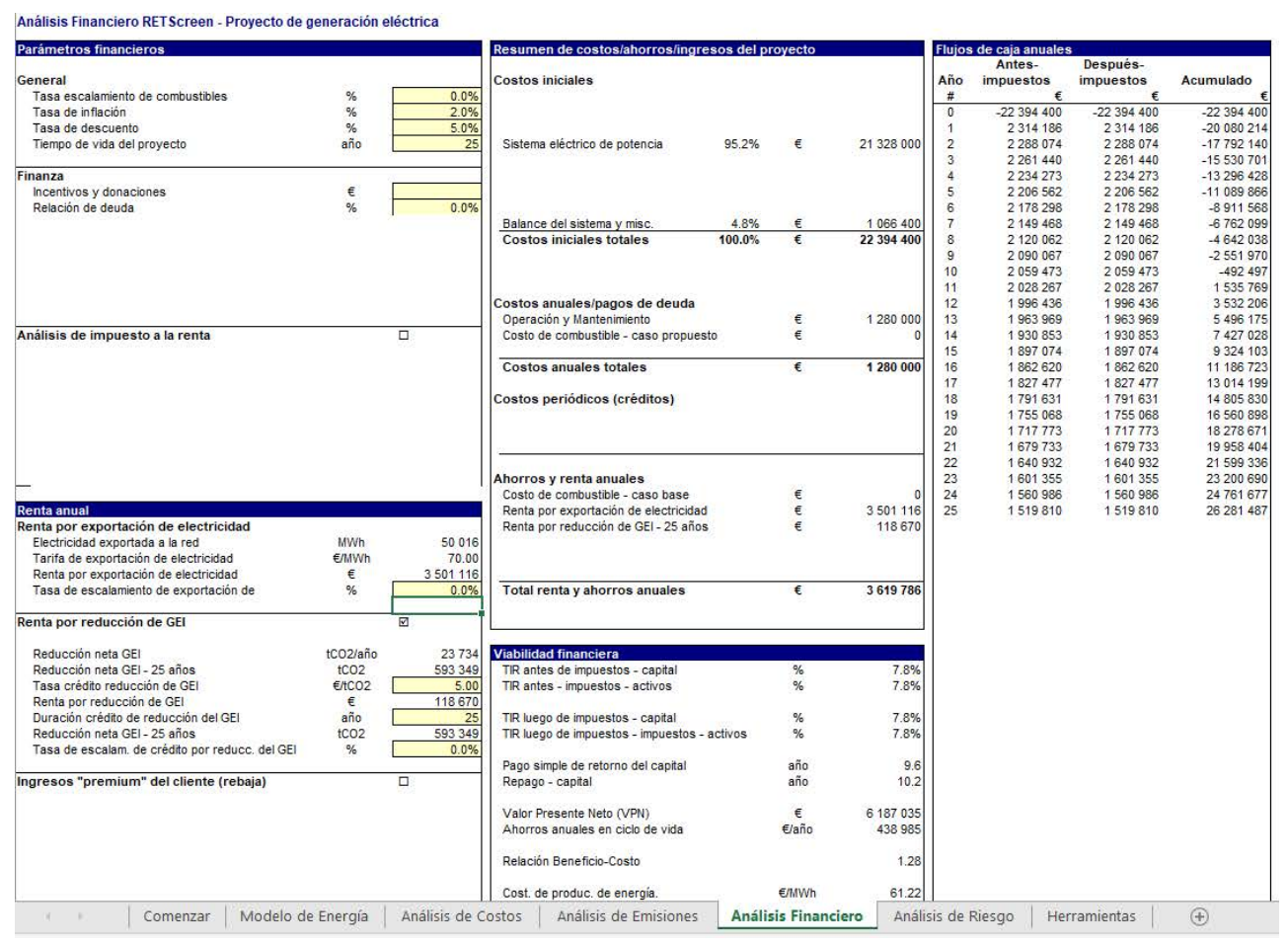

Figure 5. View of Retscreen (c) economic viability calculation screen.

In this first year of the using the PBL method, the evaluation consisted of requiring the students to write a short 5-page report explaining the different phases of the project.

However, conscious of the limited time available to the students to write a report on the practices, next year we will propose that they answer a questionnaire through the UPV's Politformat "exams" with some short open questions and some closed, so that on printing the questionnaire the students will have a procedure available for verifying the economic viability of a wind farm tailored to their chosen sites.

\section{RESULTS}

After carrying out the activity within the subject, a preliminary study was made of the results obtained. The previous year, in anticipation, the E\&SD students had answered a questionnaire on an online platform during class hours in which each question had four options, with only one correct, and a limited time for each question. The same questionnaire was given to this year's students after the PBL practice experience.

The questionnaire contained 20 questions in three blocks on purely theoretical concepts, calculations, and taking decisions under certain conditions.

In both cases the evaluation date had not been revealed beforehand, although they were aware that it would be after the activity.

Participation was high in both cases: 31 and 36 students.

The remaining contour variables were kept stable from one year to the next: the same syllabus, same lecturers, class activities, timetables, same evaluation time. The only different activity was the practice experience described here under the conceptual development and practice as a project, and the activity that the previous year's students had done in first-year GIE Statistics (Table 1). 
Table 1. Questionnaire

\begin{tabular}{cc}
\hline No $^{\circ}$ questions & 20 \\
Dimensions & 3 \\
$\mathrm{~N}^{\circ}$ options per question & 4 \\
$\mathrm{~N}^{\circ}$ students & $31-36$ \\
Limited time & Yes \\
Other Variables & Constant \\
\hline
\end{tabular}

All the participants answered all the questions. The results obtained showed that in general the number of correct answers increased by $40.85 \%$, which is clearly significant if we test the hypothesis of whether or not the number of correct answers rose, with practically null p-values.

With regard to the questions formulated (Table 2), there was a significant increase in the percentages of correct answers to 8 of the 20 questions, with p-values of the increase hypothesis in this percentage between 0.02 and 0.0011 . Of the remaining 12 questions, 2 presented an increase of of $46 \%$ and $100 \%$, which puts them on the borders of the acceptability of the hypothesis with p-values close to 0.05 .

Table 2. Results of analysis by questions and dimensions

\begin{tabular}{lccc}
\hline & Increase & Percentage Increase & p-value \\
\hline Q1 & 14.96 & 46.37 & 0.0840 \\
Q2 & 6.99 & 72.21 & 0.2182 \\
Q3 & 38.17 & 69.60 & 0.0053 \\
Q7 & 2.42 & 10.72 & 0.4199 \\
Q9 & 27.15 & 325.93 & 0.0103 \\
Q17 & 8.69 & 62.56 & 0.2052 \\
Calculation Dimension & 16.40 & 95.14 & 0.0474 \\
\hline Q4 & 2.42 & 10.72 & 0.4199 \\
Q5 & 7.17 & 14.82 & 0.3428 \\
Q8 & 21.33 & 330.70 & 0.0198 \\
Q11 & -4.92 & -13.87 & 0.6370 \\
Q12 & 24.64 & 109.12 & 0.0465 \\
Q13 & 35.66 & 1104.02 & 0.0011 \\
Q14 & -5.28 & -9.09 & 0.6141 \\
Theoretical Dimension & 11.57 & 41.17 & 0.2101 \\
\hline Q6 & -0.72 & -1.59 & 0.5175 \\
Q10 & 41.76 & 215.81 & 0.0042 \\
Q15 & 19.98 & 123.87 & 0.0578 \\
Q16 & -11.74 & -18.20 & 0.7350 \\
Q18 & 0.09 & 0.47 & 0.4967 \\
Q19 & 56.53 & 194.73 & 0.0014 \\
Q20 & 35.22 & 546.05 & 0.0022 \\
Critical Dimension & 20.16 & 70.56 & 0.0475 \\
\hline & & &
\end{tabular}

With regard to the dimensions (theoretical, practical, decision making and critical capacity), although almost all the questions showed a higher percentage, in all the dimensions there were three or four questions with a significantly higher percentage of correct answers, especially in Calculation, in which 3 of the 7 questions improved (Figures 6, 7 and 8 and Table 2). 


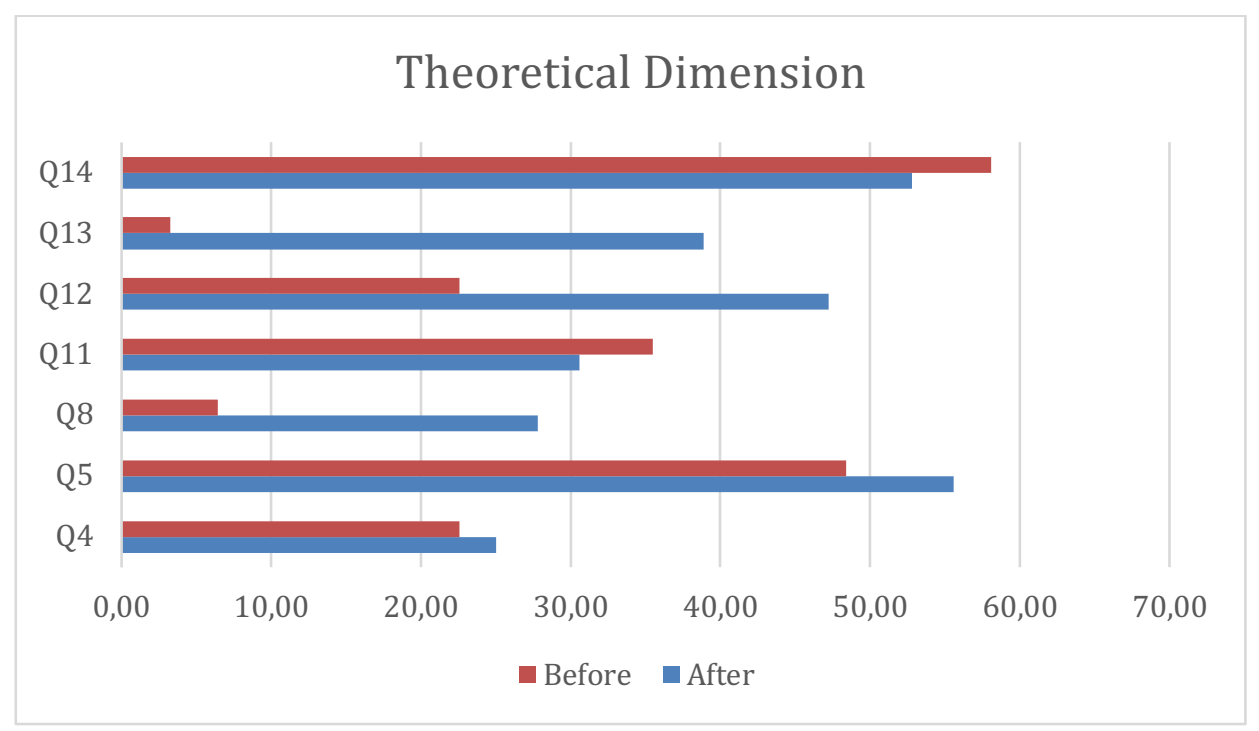

Figure 6. Percentage of correct answers in the Theoretical Dimension.

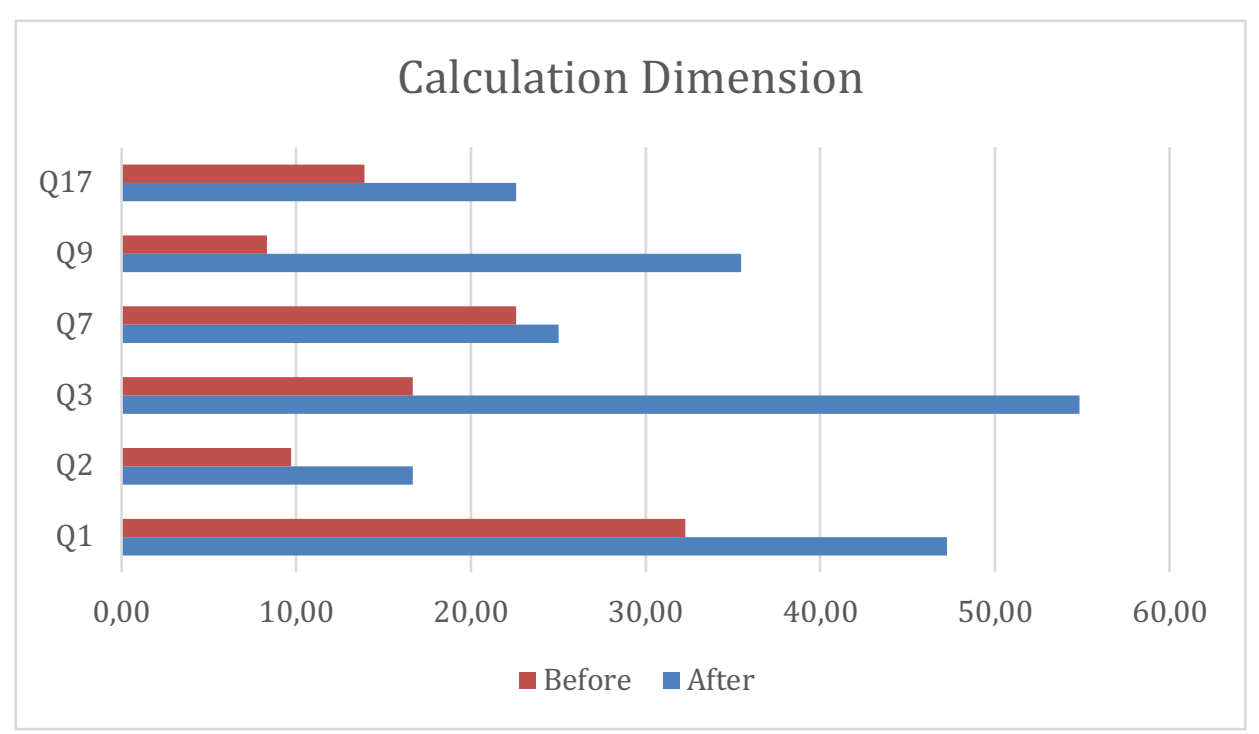

Figure 7. Percentage of correct answers in the Calculation Dimension.

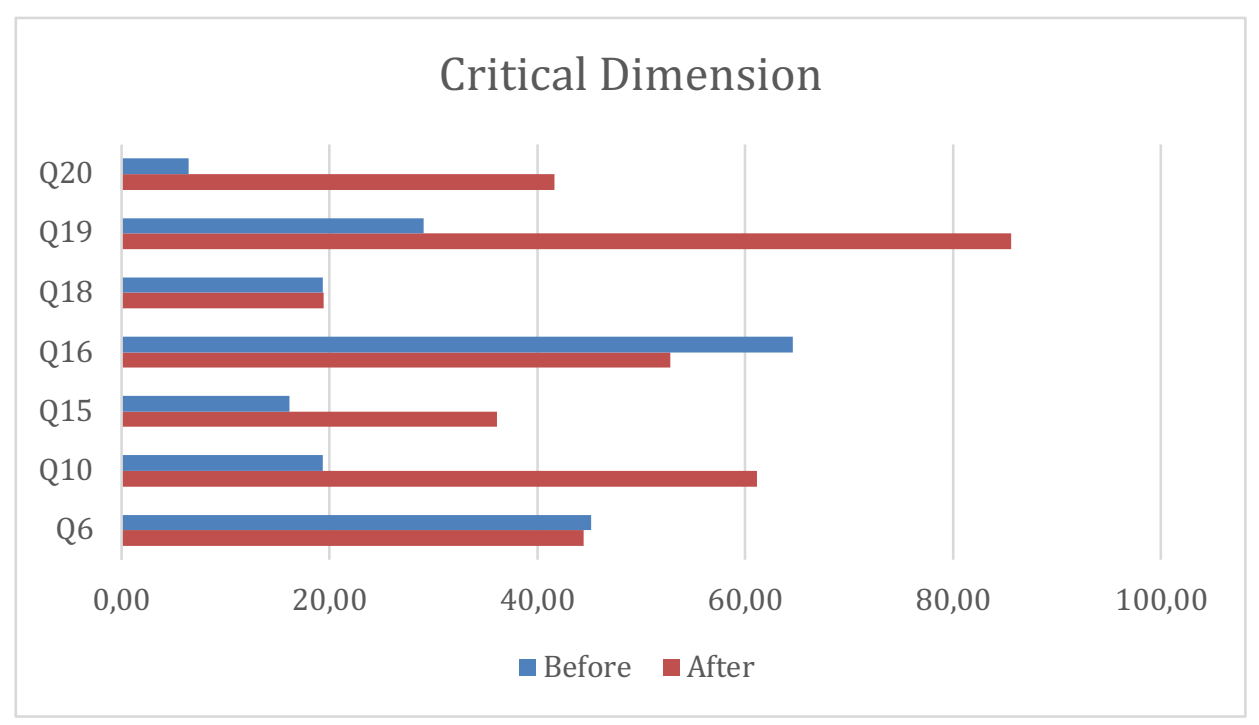

Figure 8. Percentage of correct answers in the Critical Dimension. 


\section{CONCLUSIONS}

The results show that in general the percentage of correct answers rose and in some cases significantly, with small p-values, especially in Calculation and Critical Thinking, which underlines the good results obtained from the project-based learning method in these areas. The proposed activity and the analysis of the results allow the evaluation of the subject's transversal competences.

As regards the synergy between PBL and the SDG 7, the students were able to deal with a real problem directly related to the optimization of wind power and the analysis of a project's viability, which are concepts completely integrated within the objectives of this SDG.

However, it should be noted that the results obtained were from a single year and therefore not sufficient to reach overall conclusions. It will be necessary to see the evolution in future years and the comparisons of the same dimensions with other aspects that are not dealt with in PBL.

\section{ACKNOWLEDGEMENTS}

This work was carried out within the framework of the PIME's Educational Improvement and Innovation Project 2018-2019 "Coordination of transversal competences in nuclear subjects of the Energy Engineering Degree", Referencia B16, del Vicerrectorado de Estudios, Calidad y Acreditación de la Universitat Politècnica de València.

\section{REFERENCES}

[1] GARCIA, J., PEREZ, J. (2018) Aprendizajebasado en proyectos: método para el diseño de Actividades. RevistaTecnología, Ciencia e Innovación, CEF, núm. 10 (mayo-agosto 2018, pp. 3763

[2] HUFF, J. L., ZOLTOWSKI, C. B. AND OAKES, W. C. (2016), PreparingEngineers for the Workplacethrough Service Learning: Perceptions of EPICS Alumni. Journal of Engineering Education. 105,43-69.

[3] CUIÑAS I., MARIÑO-ESPIÑEIRA P., FERNANDEZ-IGLESIAS M., CAEIRO, M., COSTAMONTENEGRO E., DIAZ-OTERO F. (2016). Evaluación de competencias con metodologíasde aprendizajebasado en proyectos. Congreso INRED 2016

[4] MARTON I., GALLARDO S., VILLANUEVA J.F., CARLOS S., SÁNCHEZ A., (2019) Aprendizajebasado en proyectos en el Grado en ingeniería de la energía, Congreso INRED 2019.

[5] NACIONES UNIDAS. (2019) Objetivos y metas de desarrollosostenible. < https://www.un.org/sustainabledevelopment/es/objetivos-de-desarrollo-sostenible/ >[consulta: Marzo 2019] . 